\begin{tabular}{c|c|c}
\hline \hline & CLIMATE RESEARCH \\
Vol. 24: 33-46, 2003 & Clim Res & Published June 10 \\
\hline
\end{tabular}

\title{
Seasonal variation of the circulation types occurring over southern Greece: a 50 yr study
}

\author{
P. A. Kassomenos*, O. A. Sindosi, C. J. Lolis \\ Laboratory of Meteorology, Department of Physics, University of Ioannina, 45110 Ioannina, Greece
}

\begin{abstract}
In this study we introduce a new procedure for grouping the circulation types occurring over an area. This procedure combines the surface air mass characteristics affecting an area with the synoptic conditions prevailing over it. Factor analysis along with cluster analysis are used to derive the circulation types, based on surface meteorological data, as well as on surface pressure grid data. The methods are applied in Athens, Greece, using data for the period 1954-1999. The circulation types are analyzed daily at the sea surface; their temporal evolution is also examined via transition matrices. A total of 315 grid points were used in the area $25-60^{\circ} \mathrm{N}, 10^{\circ} \mathrm{W}-40^{\circ} \mathrm{E}$. This analysis derived 8 circulation types for the cold period of the year and 6 for the warm period. The annual and monthly frequency distributions of these types are analyzed. Annual and interannual trends of the types as well as their persistence for 1 and $2 \mathrm{~d}$ after their occurrence are examined, as is the transition of one type to another.
\end{abstract}

KEY WORDS: Circulation types $\cdot$ Regional climate $\cdot$ Factor analysis $\cdot$ Cluster analysis $\cdot$ Transition matrices $\cdot$ Athens $\cdot$ Southern Greece

Resale or republication not permitted without written consent of the publisher

\section{INTRODUCTION}

Synoptic classification schemes are increasingly popular in explaining links between climate and a wide variety of environmental problems, such as air quality, morbidity, water quality, precipitation, natural disasters and agricultural applications. There are numerous works proposing synoptic classification schemes for various kinds of applications. The synoptic classification methods are either manual or computerbased.

Manual classification of atmospheric circulation has been widely used in the past. According to this method, investigators examine weather maps and classify circulation types in accordance to the position of the pressure centers, gradients, etc. (Lamb 1972, Maheras 1988, Kassomenos et al. 1998, among others). The major drawback of this technique is that it relies on the subjectiveness of the investigator and his experience.

The computer-based methods use various meteorological parameters, such as temperature, cloudiness, radiation and humidity, from 1 or more surface or upper-air stations in order to identify the previously mentioned properties. The classification is based on statistical techniques such as principle-component analysis (PCA) and cluster analysis (CA) (Yarnal 1992, Matyasovsky 1995, McGregor \& Bamzelis 1995, among others), orthogonal transformations between principal components and original variates (Yao 1998) and, recently, neural networks and fuzzy logic techniques (Bardossy et al. 1995, Hewitson \& Crane 2002). These methods could be characterized as objective, since they do not rely upon the investigator's knowledge and judgment. They do, however, introduce limitations on the form of the data and on the physical interpretation of the results. There is extensive literature concerning the statistical techniques usually used for the 'objective' methods. Kalkstein et al. (1987) compared 3 clustering procedures in order to select the most suitable synoptic classification scheme. Recently, a spatial synoptic classification was introduced to assess the character and the frequency of air masses (Kalkstein et al. 1998). 
Much of the synoptic classification was performed using PCA with various types of rotations (Yarnal 1992), followed by CA (hierarchical or not; McGregor \& Bamzelis 1995). PCA is applied on the original time series for the reduction of the number of variables and the CA is applied on the principal components scopes for an objective grouping of the cases (days or years; Davis \& Walker 1992).

In this paper a combined factor and cluster analysis technique was used in order to develop a classification scheme for circulation types occurring over an area. The analysis was applied not only to the meteorological parameters of the specific site, but also to the time series of the sea-level atmospheric pressure over Europe. The latter is an innovative technique that combines the air-mass characteristics (as represented by the analysis of meteorological parameters) and the synoptic conditions (as represented by the sea-level atmospheric pressure data series).

The method was applied for the area of Athens, located in a small (about $450 \mathrm{~km}^{2}$ ) basin, the only site in southern Greece for which such an extended and reliable meteorological database exists. As far as the authors know, little work has been done to analyze the circulation types over this overpopulated area. Kassomenos et al. (1998) analyzed the synoptic conditions for a 15 yr period using a manual classification procedure for the isobaric level of $850 \mathrm{hPa}$. In the present work, the 'objective' method is applied on surface data covering a period of almost $50 \mathrm{yr}$ (1954-1999) and studies both the short-term (a few days after the occur-

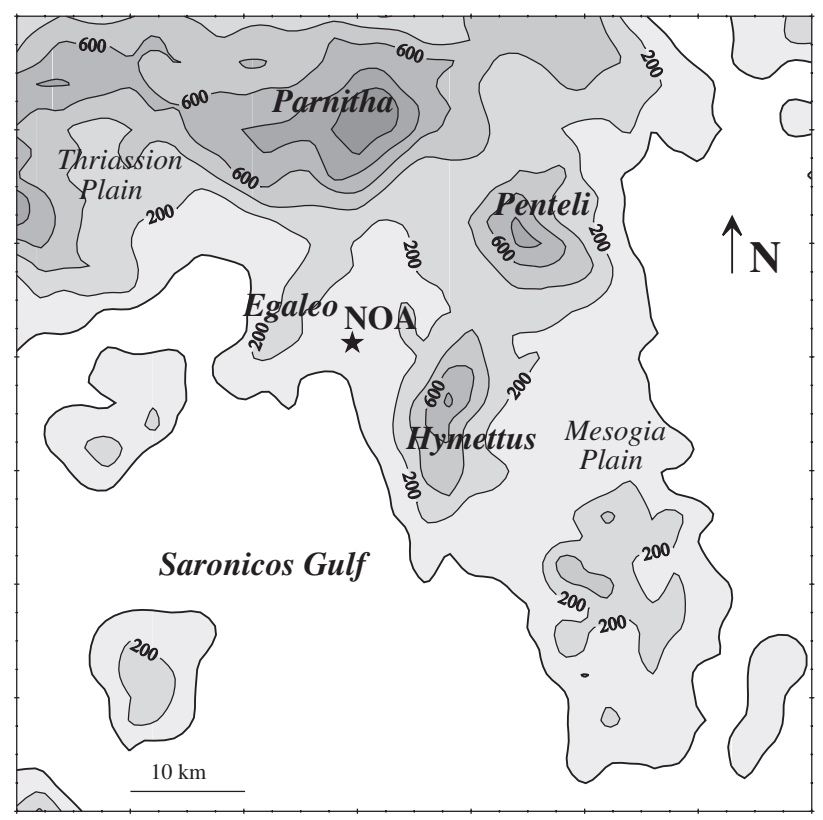

Fig. 1. Topography of the greater Athens area. NOA: National Observatory of Athens rence of a circulation type) and the long-term (annual trends for 46 yr period) temporal evolution of the circulation types.

The data used and the methodology adopted are discussed in Section 2. In Section 3 the results from the analysis are presented for the cold and warm period of the year separately. In Section 4, the short and long temporal variations of the synoptic condition frequencies are examined, while in Section 5 the most significant conclusions are drawn.

\section{DATA AND METHODS}

The data used consists of daily values of: (1) 11 meteorological parameters recorded by the National Observatory of Athens (NOA). These parameters are the following: mean, maximum and minimum air temperature $\left(T_{\text {mean }}, T_{\max }, T_{\min }\right)$, diurnal temperature range $\left(T_{\text {range }}\right)$, total solar radiation (SR), mean relative humidity $(\mathrm{RH})$, mean water vapor pressure $(e)$, mean atmospheric pressure $(P)$, mean wind speed (WS) and mean prevailing wind velocity components in the WNW-ESE and SSW-NNE directions ( $u^{\prime}$ and $v^{\prime}$ respectively). The components $u^{\prime}$ and $v^{\prime}$ are used instead of $u$ and $v$ (W-E and $\mathrm{S}-\mathrm{N}$ respectively), taking into account the coastline and the Athens basin axes directions (Fig. 1). (2) Sea-level atmospheric pressure at 315 grid points in the area $25-60^{\circ} \mathrm{N}, 10^{\circ} \mathrm{W}-40^{\circ} \mathrm{E}$, with a $2.5^{\circ} \times 2.5^{\circ}$ grid, for the period 1954-1999 (46 yr). These data were recorded at 12:00 $\mathrm{h}$ UTC and were provided by NCEPNCAR (Kalnay et al. 1996). This practically means that phenomena with timescales smaller than $24 \mathrm{~h}$ could not be identified.

The statistical methods used in this work are factor analysis (FA) and cluster analysis (CA); they are briefly described in the following.

FA is a data reduction technique, describing a set of $p$ variables, $X_{1}, X_{2}, \ldots, X_{\mathrm{p}}$ in terms of a smaller number of new uncorrelated parameters, the factors. Each of the initial variables, $X_{i}$ can be expressed as a linear function of $m(m<p)$ factors,

$$
X_{i}=a_{i 1} F_{1}+a_{i 2} F_{2}+\ldots+a_{i m} F_{m}
$$

where $F_{1}, F_{2}, \ldots, F_{m}$ are the factors and $a_{i 1}, a_{i 2}, \ldots, a_{i m}$ are the factor loadings which express the correlation between the initial variables and the factors. The values of each factor are called factor scores (Jolliffe 1986). The number $m$ of the statistically significant factors has to be decided upon using various rules (Jolliffe 1986) and considering the physical interpretation of the results. Finally, a widely used process is the rotation of the axes, which creates new factors with different variances, keeping the cumulative variance of the $m$ factors unaffected. Among the various types of rota- 
tion, varimax rotation is generally accepted as the most accurate orthogonal rotation (Richman 1986).

CA classifies the $n$ observations of $p$ variables into objectively defined groups, the clusters, such that each cluster is as homogeneous as possible with respect to the clustering variables. The first step in CA is to select a measure of similarity. Second, a decision is made on the type of clustering technique to be used (e.g. a hierarchical or a nonhierarchical one). Third, the type of clustering method for the selected technique is selected, and fourth, a decision regarding the number of clusters is made. Finally, the cluster solution is interpreted (Sharma 1995). In the present work, the squared Euclidean distance

$$
D_{i j}^{2}=\sum_{k=1}^{p}\left(X_{i k}-X_{j k}\right)^{2}
$$

is used as a measure of similarity, while the $k$-means technique of the non-hierarchical clustering approach is selected. The above technique allows the rearrangement of the observations once they have been classified into a group, by optimizing the final classification (Davis \& Walker 1992, Kalkstein et al. 1996).

In this work, FA is applied on the time series of the NOA meteorological parameters and sea-level-pressure values at 315 grid points separately. The $u^{\prime}$ wind component was not included in the analysis because of the high divergence of this parameter from the normal distribution (too many zero values).

Then, CA is applied on a new group of variables. These are the time series of the factor scores produced by the factor analysis. This procedure, i.e. the application of CA not only on the data reduction products of the in situ measured meteorological parameters but on a composite group of variables including over and above atmospheric pressure variations over a major area around the station, has never been applied before as far as we are aware. This approach was followed in the present work in order to make the classification on a different and more complete basis. By doing so, classification is not based only on the in situ meteorological conditions, but also on the synoptic conditions prevailing over a greater area around the station. This approach allows the separation of the observations presenting the same air mass characteristics over the station but referring to different synoptic patterns. In other words, if 2 days have the same levels of temperature, humidity, radiation, etc., in the area of the station but these conditions are due to 2 non-identical synoptic systems, these 2 days are considered as different and they are classified into 2 different clusters. On the other hand, if the station area is affected by the same synoptic system during 2 different days but the meteorological conditions are not the same, because of the influence of local factors, the above analysis will classify the days in different groups. Thus, the analysis differentiates from those of the past that were based only on meteorological conditions or only on the synoptic patterns affecting an area. The mean values of the 11 meteorological parameters are computed, and the mean synoptic sea-level-pressure patterns are constructed for each resultant cluster.

The analysis is applied separately for 2 sub-periods of the year: the first between October 16 and April 15 (cold period) and the second from April 16 to October 15 (warm period). This separation is necessary because of the different general and local atmospheric circulation regimes that characterize the 2 seasons. Generally, the cold period is characterized by the variation of weather and from a variety of conditions that change rapidly from day to day. In contrast, the warm period is characterized by more persistent and stagnant conditions.

\section{RESULTS}

\subsection{Cold period}

For the cold period, the application of FA to the time series of the 10 meteorological parameters yielded 4 factors accounting for $88 \%$ of the total variance, while the application of FA to the time series of sea-level pressure over Europe yielded 5 factors accounting for $83 \%$ of the total variance. CA was then applied to the 9 resultant factor scores time series, leading to 8 clusters. The mean values of the meteorological parameters of the NOA for the days classified in each cluster are presented in Table 1. Fig. 2 illustrates the meansea-level-pressure patterns for each cluster. The seasonal distribution of the frequency of occurrence is presented for each cluster in Fig. 3.

The days classified in Cluster $1 \mathrm{~W}$ are characterized by low radiation and high humidity levels (Table 1), while the mean sea-level pressure shows a low-pressure system west of Italy (Fig. 2a). This system causes a weak easterly flow over Athens (Table 1, Fig. 2a). It is well known that an airflow with an easterly component creates, in general, humid conditions over Athens, because of the water vapor absorbed as the air mass crosses the Aegean Sea. These conditions are usually accompanied by extensive cloudiness, responsible for the low radiation levels. According to Fig. 3a, Cluster $1 \mathrm{~W}$ is more frequent from November to January (60\% of the total number of cases).

The main characteristics of Cluster 2W are the low temperature levels and the relatively strong northerly flow (Table 1), while, according to the mean-sea-levelpressure patterns, the area is governed by a combination of an anticyclone located over the West and Central Europe and the Cyprus low system (Fig. 2b). This synoptic pattern is accompanied by a northerly flow 
Table 1. Total number of cases and the mean daily values of the meteorological parameters for the 8 cold-period clusters. SR: total

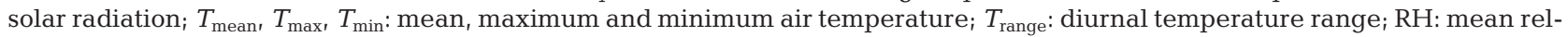
ative humidity; $P$ : mean atmospheric pressure; WS: mean wind speed; $u^{\prime}, V^{\prime}$ : mean prevailing wind velocity components in the WNW-ESE and SSW-NNE directions, respectively; e: mean water vapor pressure

\begin{tabular}{|c|c|c|c|c|c|c|c|c|c|c|c|c|}
\hline & Cases & $\begin{array}{c}\mathrm{SR} \\
\left(\mathrm{MJ} \mathrm{m}^{-2}\right)\end{array}$ & $\begin{array}{c}T_{\text {mean }} \\
\left({ }^{\circ} \mathrm{C}\right)\end{array}$ & $\begin{array}{l}T_{\max } \\
\left({ }^{\circ} \mathrm{C}\right)\end{array}$ & $\begin{array}{l}T_{\min } \\
\left({ }^{\circ} \mathrm{C}\right)\end{array}$ & $\begin{array}{l}T_{\text {range }} \\
\left({ }^{\circ} \mathrm{C}\right)\end{array}$ & $\begin{array}{l}\text { RH } \\
(\%)\end{array}$ & $\begin{array}{c}P \\
(\mathrm{~mm} H g)\end{array}$ & $\begin{array}{c}\text { WS } \\
\left(\mathrm{m} \mathrm{s}^{-1}\right)\end{array}$ & $\begin{array}{c}V^{\prime} \\
\left(\mathrm{m} \mathrm{s}^{-1}\right)\end{array}$ & $\begin{array}{c}u^{\prime} \\
\left(\mathrm{m} \mathrm{s}^{-1}\right)\end{array}$ & $\begin{array}{c}e \\
(\mathrm{~mm} \mathrm{Hg})\end{array}$ \\
\hline Cluster 1W & 1090 & 6.7 & 12.2 & 15.3 & 9.7 & 5.6 & 79 & 753.3 & 2.0 & -0.3 & -0.4 & 11.5 \\
\hline Cluster 2W & 933 & 8.1 & 7.5 & 10.4 & 5.3 & 5.1 & 69 & 751.2 & 3.3 & -2.4 & 0.7 & 7.4 \\
\hline Cluster 3W & 719 & 8.7 & 10.2 & 12.6 & 8.4 & 4.2 & 66 & 757.4 & 6.2 & -5.8 & -0.9 & 8.6 \\
\hline Cluster $4 \mathrm{~W}$ & 1024 & 7.6 & 12.9 & 15.9 & 10.2 & 5.7 & 75 & 745.7 & 3.4 & 2.0 & -0.1 & 11.4 \\
\hline Cluster 5W & 1048 & 17.1 & 14.1 & 18.7 & 10.4 & 8.3 & 62 & 749.6 & 2.3 & 0.8 & 0.6 & 10.3 \\
\hline Cluster 6W & 1192 & 10.2 & 16.1 & 20.2 & 13.0 & 7.2 & 76 & 753.1 & 1.6 & 0.7 & -0.2 & 14.2 \\
\hline Cluster 7W & 1140 & 8.9 & 10.0 & 14.1 & 6.8 & 7.3 & 71 & 758.1 & 1.6 & -0.6 & 0.0 & 9.0 \\
\hline Cluster 8W & 944 & 13.7 & 12.5 & 17.5 & 8.7 & 8.8 & 62 & 756.5 & 1.8 & -0.5 & 0.2 & 9.3 \\
\hline
\end{tabular}

with cold advection over Athens. It appears (Fig. 3b) that this pattern is more frequent during late winter (January-March) - almost two-thirds of the total number of cases.

The main feature of Cluster $3 \mathrm{~W}$ is the strong N-NE flow, as shown in Table 1 (high negative $v^{\prime}$ ). In Fig. 2c, it can be seen that an anticyclone located over Eastern Europe causes a very strong pressure gradient over the Balkans. Although the flow has an easterly component, the air mass is relatively dry, since its time in contact with the water surface is short, due to the predominantly high wind speed. An impressive characteristic of this pattern is its high frequency during late October (Fig. 3c) - one-third of the total number of cases.

Cluster $4 \mathrm{~W}$ is characterized by low atmospheric pressure, high humidity and relatively strong southerly flow (Table 1). The corresponding pressure patterns show enhanced cyclonic activity over Italy and the north Ionian Sea (Fig. 2d). This synoptic condition is responsible for strong southerly flow, extensive cloudiness and warm advection over Athens. The seasonal distribution of Cluster 4 presents a maximum during the conventional winter, December-February (Fig. 3d) - more than two-thirds of the total number of cases.

The main features of Cluster 5W are the high radiation levels, the low relative humidity and the high diurnal temperature range (Table 1). According to the surface pressure pattern (Fig. 2e), it can be seen that there is a weak westerly flow over Athens. This is not apparent in Table 1, from which it seems that there is no prevailing wind direction. This is possibly due to local circulation cells resulting from the relatively high radiation levels, although the short sunshine duration and the relatively high soil moisture amounts do not allow, in general, the establishment of full-scale local circulation systems. This cluster can be characterized as a spring one, because it is very frequent during the spring months March and April (Fig. 3e) - about threequarters of the total number of cases.

Cluster 6W can be characterized as warm and humid, as they present the highest values of temperature and water vapor pressure (Table 1). In Fig. $2 \mathrm{f}$ it is shown that there is a southerly flow over Athens, causing warm advection from North Africa. This advection can be considered responsible for the high temperatures. This cluster can be characterized as an autumn one, because its frequency takes its maximum value during October and November (Fig. 3f) $-60 \%$ of the total number of cases.

Cluster 7W can be considered as anticyclonic, and its features support this statement. The atmospheric pressure is the highest, the diurnal temperature range is also high and the winds are weak. The anticyclonic activity is apparent at the surface (Fig. 2g). These conditions are more frequent during December and January (Fig. $3 \mathrm{~g}$ ) - about $60 \%$ of the total number of cases.

Finally, generally high temperatures, high diurnal temperature range and high radiation levels characterize Cluster $8 \mathrm{~W}$. In Fig. $2 \mathrm{~h}$ it is shown that there is a weak pressure gradient over Greece and Turkey, causing a generally weak northerly flow. This cluster is more frequent during spring and autumn (Fig. 3h) more than three-quarters of the total number of cases.

\subsection{Warm period}

For the warm period of the year, the application of FA on the time series of the 10 meteorological parameters yielded 4 factors accounting for $88 \%$ of the total variance, while the application of FA on the time series of sea-level pressure over Europe yielded 7 factors accounting for $84 \%$ of the total variance. CA was then applied on the 11 resultant factor scores time series, 

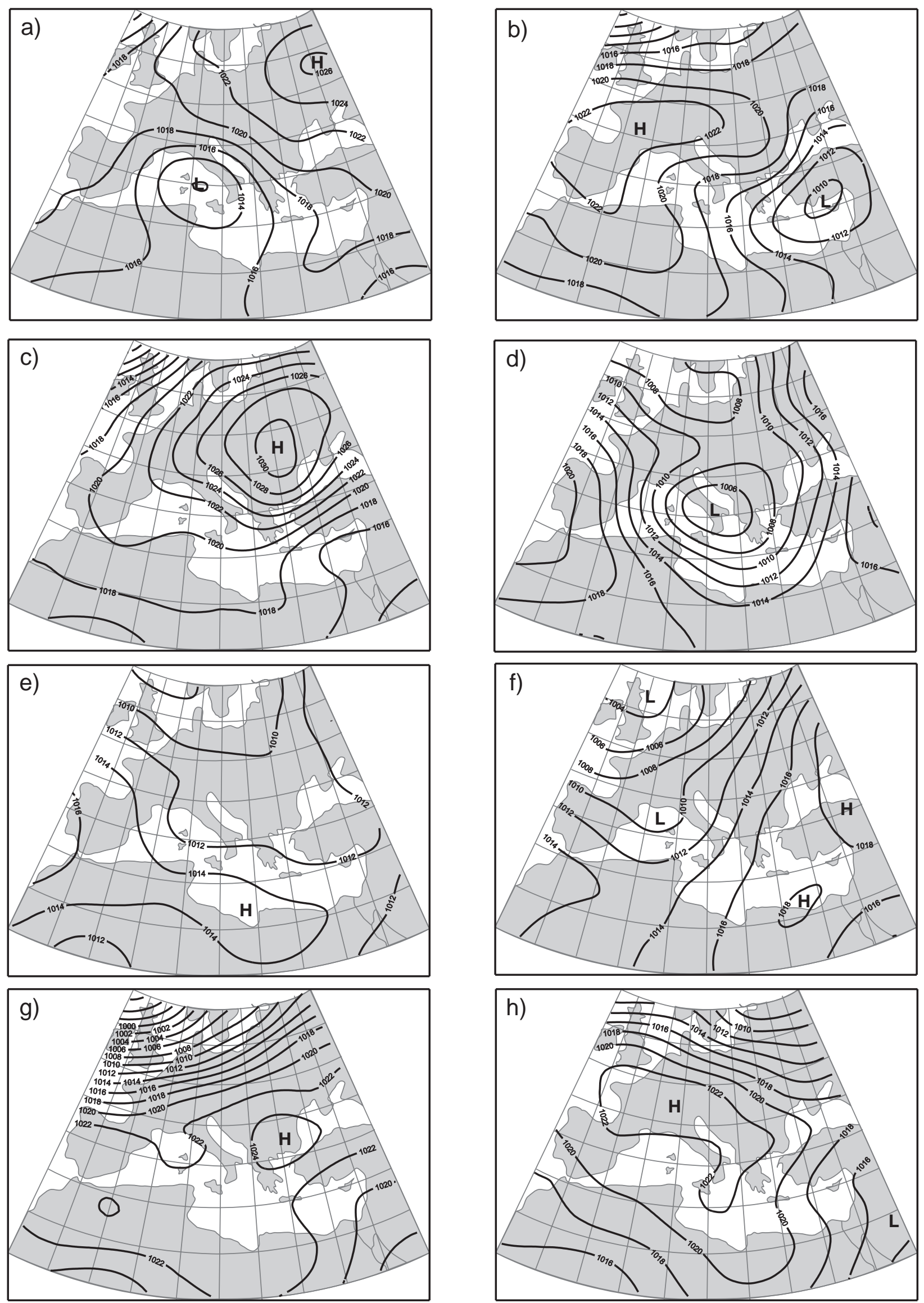

Fig. 2. Sea-level pressure (hPa) patterns corresponding to the 8 cold-period clusters 
leading to 6 clusters. The mean values of the meteorological parameters for the days classified in each cluster are presented in Table 2. Fig. 4 shows the meansea-level-pressure patterns for each cluster. The seasonal distribution of the frequency of occurrence is presented for each cluster in Fig. 5.

a)

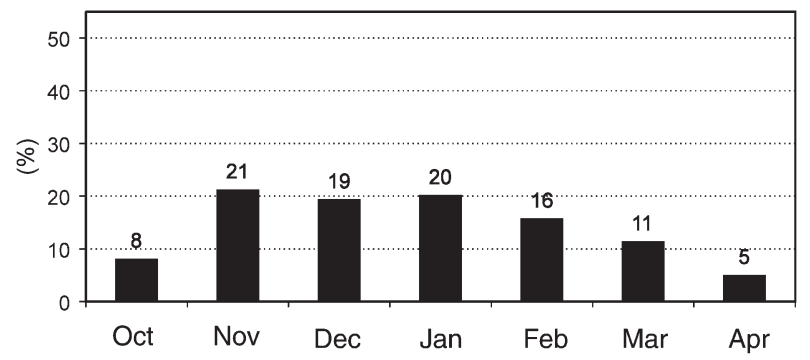

c)

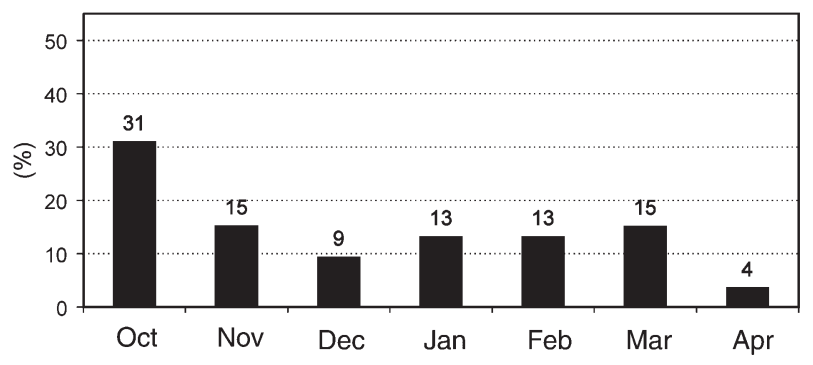

e)

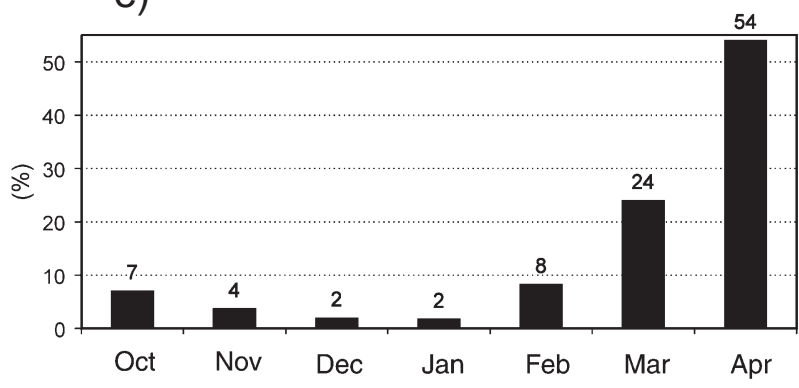

g)

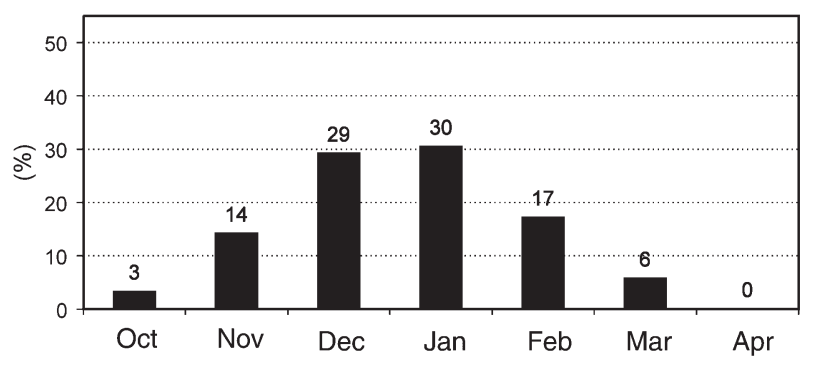

Cluster 1S consists of days between the cold and warm periods, as it appears to be more frequent during April and May (Fig. 5a) and rather rare during the high summer months (June, July and August). The main feature of this cluster is the presence of a low-pressure system over the Balkans and Italy (Fig. 4a). The surface system is

b)

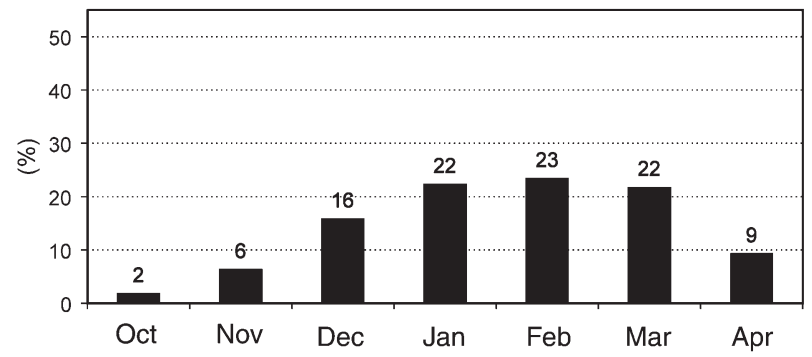

d)

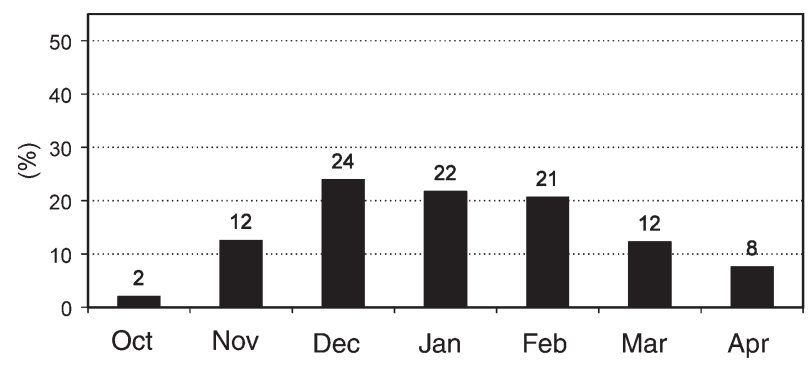

f)

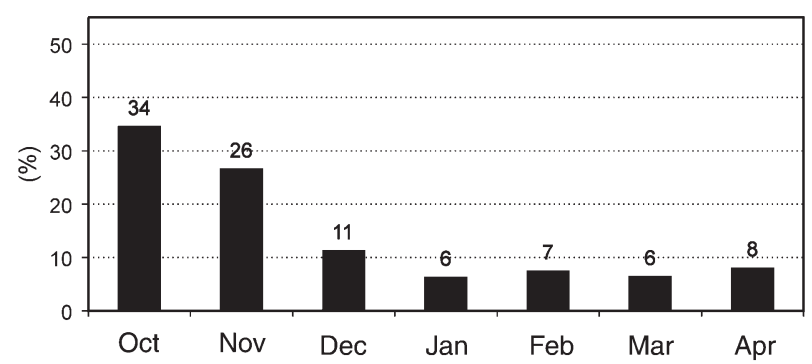

h)

CLUSTER 8W

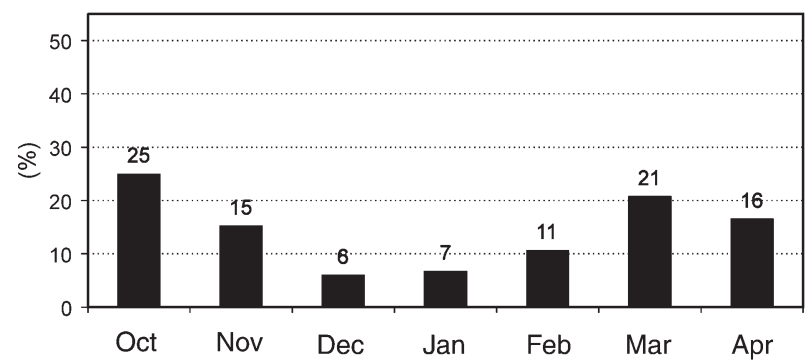

Fig. 3. Seasonal distribution of the frequency (\%) of the 8 cold-period clusters 
Table 2. Total number of cases and the mean daily values of the meteorological parameters for the 6 warm-period clusters. For variable definitions, see Table 1

\begin{tabular}{|c|c|c|c|c|c|c|c|c|c|c|c|c|}
\hline & Cases & $\begin{array}{c}\mathrm{SR} \\
\left(\mathrm{MJ} \mathrm{m}^{-2}\right)\end{array}$ & $\begin{array}{l}T_{\text {mean }} \\
\left({ }^{\circ} \mathrm{C}\right)\end{array}$ & $\begin{array}{l}T_{\max } \\
\left({ }^{\circ} \mathrm{C}\right)\end{array}$ & $\begin{array}{l}T_{\min } \\
\left({ }^{\circ} \mathrm{C}\right)\end{array}$ & $\begin{array}{l}T_{\text {range }} \\
\left({ }^{\circ} \mathrm{C}\right)\end{array}$ & $\begin{array}{l}\mathrm{RH} \\
(\%)\end{array}$ & $\begin{array}{c}P \\
(\mathrm{~mm} \mathrm{Hg})\end{array}$ & $\begin{array}{c}\mathrm{WS} \\
\left(\mathrm{m} \mathrm{s}^{-1}\right)\end{array}$ & $\begin{array}{c}V^{\prime} \\
\left(\mathrm{m} \mathrm{s}^{-1}\right)\end{array}$ & $\begin{array}{c}u^{\prime} \\
\left(\mathrm{m} \mathrm{s}^{-1}\right)\end{array}$ & $\begin{array}{c}e \\
(\mathrm{~mm} \mathrm{Hg})\end{array}$ \\
\hline Cluster 1S & 1215 & 19.7 & 20.8 & 25.3 & 17.3 & 8.0 & 63.5 & 748.2 & 2.1 & 1.2 & 0.5 & 16.1 \\
\hline Cluster 2S & 779 & 19.0 & 21.0 & 25.0 & 17.9 & 7.1 & 52.4 & 754.2 & 5.2 & -4.8 & -0.8 & 13.3 \\
\hline Cluster 3S & 2121 & 24.5 & 26.9 & 32.5 & 22.3 & 10.2 & 50.5 & 749.2 & 1.8 & 0.7 & 0.5 & 18.4 \\
\hline Cluster 4S & 1426 & 24.6 & 26.8 & 31.7 & 22.8 & 8.9 & 44.6 & 750.6 & 3.9 & -3.3 & -0.3 & 16.1 \\
\hline Cluster 5S & 1584 & 19.1 & 22.1 & 27.5 & 17.8 & 9.7 & 58.6 & 753.6 & 1.6 & -0.2 & 0.1 & 16.0 \\
\hline Cluster 6S & 1158 & 23.5 & 19.3 & 24.3 & 15.1 & 9.2 & 56.6 & 751.4 & 2.0 & 0.8 & 0.5 & 13.0 \\
\hline
\end{tabular}

relatively weak, in contrast to the respective systems appearing during the cold period. Because of the weak pressure gradient, wind speed is relatively low while the wind direction is southwesterly. Air temperature and total radiation are low because this cluster occurs mainly in the beginning of the warm period (Table 2).

Cluster 2S corresponds to Cluster 3W, as it is frequent during September and October (Fig. 5b) - about $60 \%$ of the total number of cases. Pressure distribution is characterized by a high barometric system over Central and Eastern Europe, causing an intense pressure gradient over Turkey and the Aegean Sea (Fig. 4b). The wind is strong and blows from northerly directions. Despite the fact that total radiation and air temperature are at the same levels as in Cluster 1S, watervapor pressure and thus relative humidity in Cluster $2 \mathrm{~S}$ have lower values (Table 2). This modification can be attributed to the fact that the air masses in Cluster 1S move more slowly above the Aegean Sea and absorb higher amounts of water vapor. On the other hand, the air masses affecting the Athens area during Cluster 2S days have crossed the Aegean Sea faster because of the high wind speed.

Cluster $3 \mathrm{~S}$ is a typical summertime cluster. It presents its highest frequency during the summer months (Fig. 5c). During the days classified in this cluster, the combination between the SW Asia thermal low and the subtropical high of The Azores creates a rather weak pressure gradient over the Aegean Sea (Fig. 4c). The wind speed is relatively low, and its direction is not well determined at the surface (Table 2). Thus, some days the north synoptic wind, i.e. the so-called etesian (see e.g. Maheras 1980), prevails and $v^{\prime}$ is negative. On the contrary, on other days the weak pressure gradient and the high radiation levels favour the formation of local circulation systems, i.e. sea breezes blowing mainly from south directions, and $v^{\prime}$ is positive. Consequently, the mean of $v^{\prime}$ takes small values, indicating that the wind direction is not well determined.

Cluster 4S resembles Cluster $3 \mathrm{~S}$ with regard to total radiation and air temperature. The main difference between these 2 clusters is that in Cluster $4 \mathrm{~S}$ the pressure and height gradients over Aegean Sea are stronger than in Cluster 3S (Fig. 4c,d). The intense pressure gradient during the Cluster $4 \mathrm{~S}$ days is responsible for the well-established and generally strong northerly wind flow, i.e. the strong etesian winds dominating during July and August (Fig. 5d) - three-quarters of the total number of cases. Water-vapor pressure and relative humidity are lower than in Cluster 3S due to the short trip of the air masses over the Aegean Sea (Table 2).

Cluster 5S appears mainly during September and October (Fig. 5e), and therefore it could be characterized as autumnal. It is more frequent than the other 'early autumn' cluster (Cluster 2S) - almost $70 \%$ of the total number of cases, instead of $60 \%$ for Cluster $2 \mathrm{~S}$. This cluster is characterized by a weak pressure gradient over Athens associated with light wind conditions (Fig. 4e). Mean and maximum air temperatures as well as water-vapor pressure are higher for Cluster 5S than for Cluster $2 \mathrm{~S}$, where the mixing of atmospheric layers is stronger and the diffusion of thermal energy to higher levels is intense. Furthermore, in Cluster 2S, the air masses affecting the area come from north latitudes, keeping the air temperature low (Table 2).

Cluster 6S can be characterized as a 'late spring' one, appearing mostly during April-June (Fig. 5f). It is more frequent during these months-more than $90 \%$ of the total number of cases - compared to Cluster 1S, which also has a remarkable prevalence in the same months - about two-thirds of the total number of cases. The synoptic pattern of Cluster $6 \mathrm{~S}$ corresponds to a W-NW flow, but finally the wind blows from southerly directions due to the formation of local circulations (Fig. 4f). The total radiation is higher in Cluster 6S than in Cluster 1S, while the opposite is true for air temperature and water-vapor pressure. This can be attributed to the fact that during Cluster $1 \mathrm{~S}$ days the wind blows from the sea, transferring water vapor to Athens, leading to cloud formation and thus low radiation and high humidity levels. 

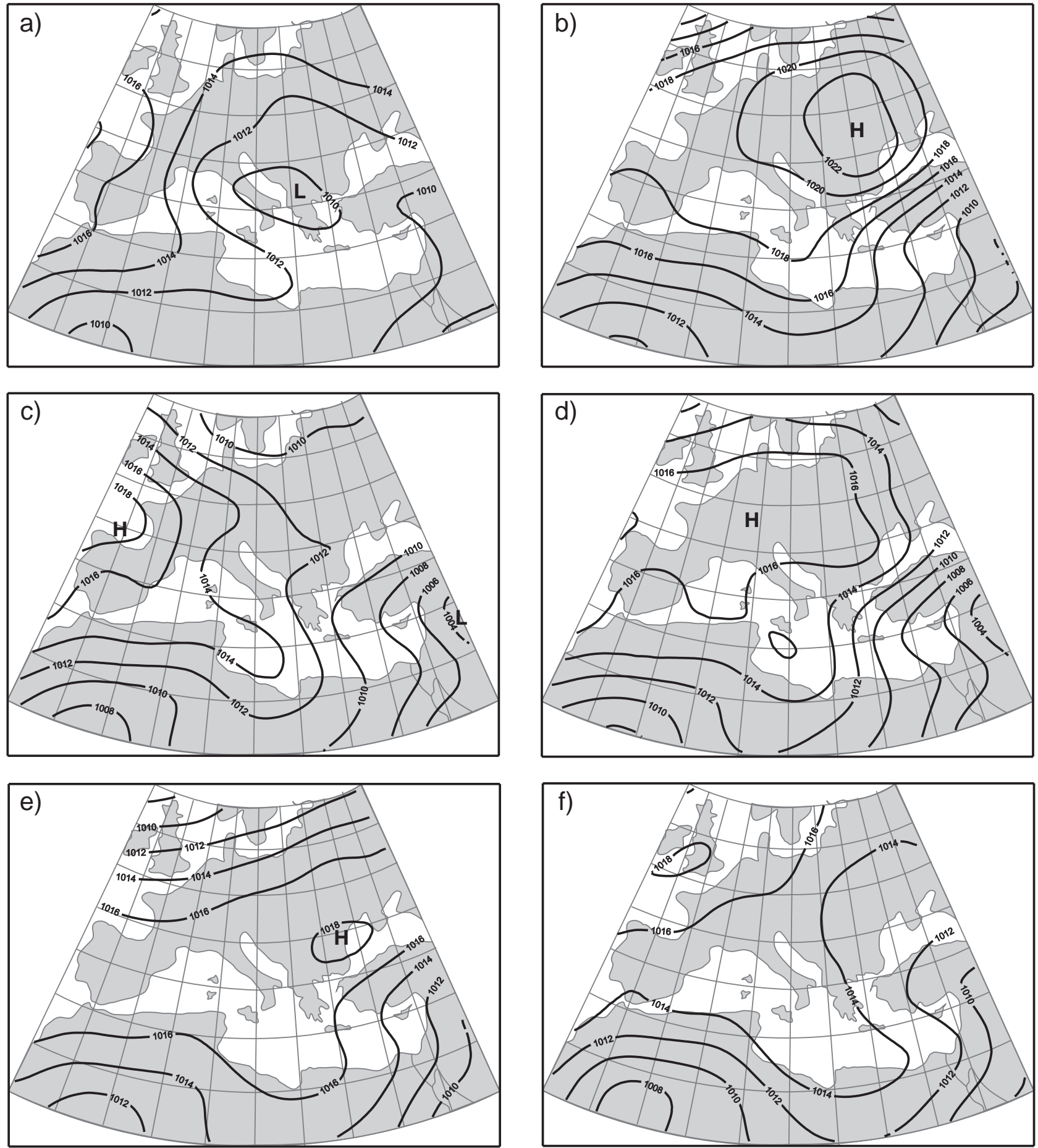

Fig. 4. Sea-level pressure patterns $(\mathrm{hPa})$ corresponding to the 6 warm-period clusters

\section{SHORT- AND LONG-TERM TEMPORAL VARIATIONS}

In this section we present (1) the interannual variations of cluster frequency and (2) the frequency distri- bution for the Days $D+1$ and $D+2$ following the Day $D$, the day of occurrence of each cluster. This provides a global view of the interannual variability, the persistence, and the time sequence of the clusters. 
a)

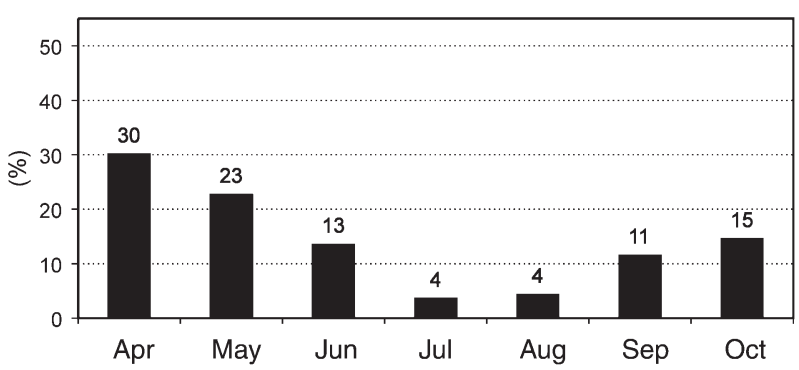

c)

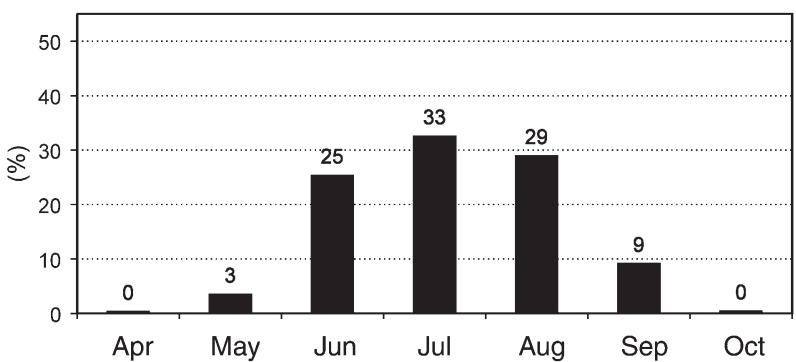

e)

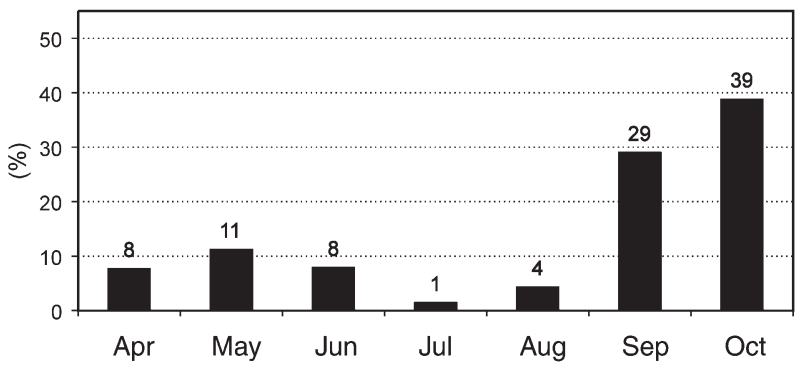

b)

CLUSTER 2S

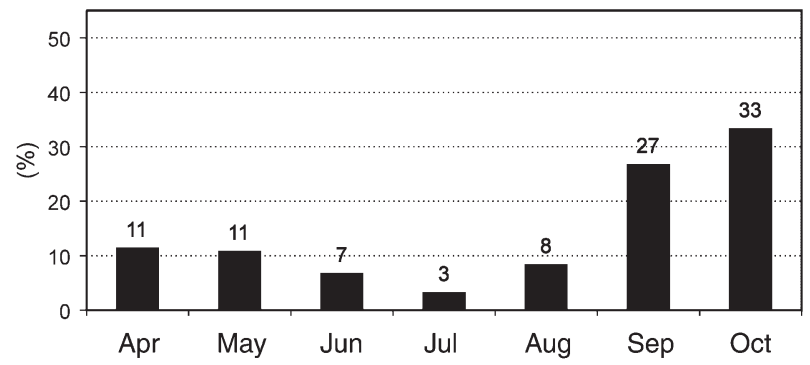

d)

\section{CLUSTER 4S}

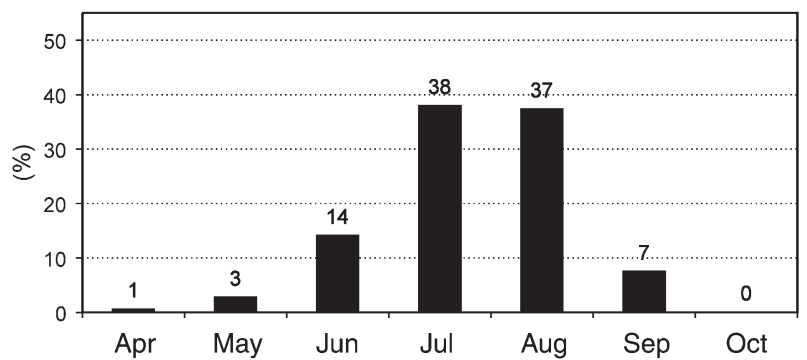

f)

CLUSTER 6S

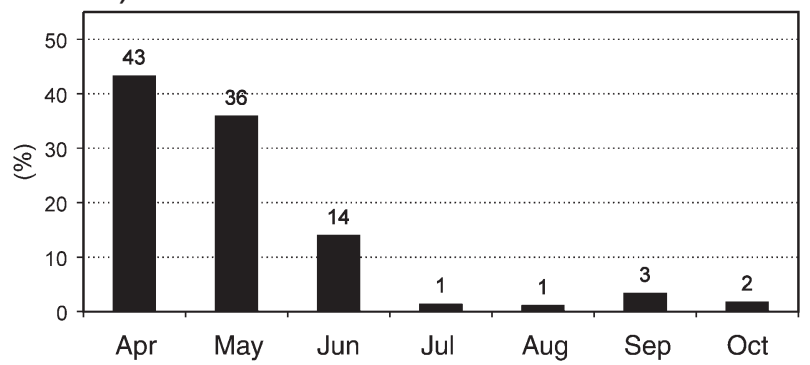

Fig. 5. Seasonal distribution of the frequency (\%) of the 6 warm-period clusters

\subsection{Cold period}

In regard to the interannual variability of the frequency of the 8 clusters (Fig. 6), we note that there is a statistically significant (95\% confidence level) negative trend in frequencies of Clusters $5 \mathrm{~W}$ and $6 \mathrm{~W}$. The frequency of Cluster $7 \mathrm{~W}$, for the period starting for the mid-1970s, is about double that of the previous period, indicating an enhanced anticyclonic activity over the Eastern Mediterranean during the last years (Xoplaki et al. 2000). The minimum of the late 1980s (1986-1989) in the frequency of occurrence of Cluster $4 \mathrm{~W}$ is in agreement with the reduction of precipitation over Greece during the same period. The main reason of this is that the low-pressure systems associated with this cluster are the main cause of precipitation over a large part of Greek territory (Xoplaki et al. 2000).

Among the 8 clusters, Clusters $6 \mathrm{~W}$ and $7 \mathrm{~W}$ appear to be the more persistent (Fig. 7) - percentages above $60 \%$ for Day $D+1$ and above $45 \%$ for Day $D+2$. This means that the weak southerly flow accompanied by high temperatures and poor ventilation conditions, as well as the common anticyclonic conditions, are more persistent than the other synoptic conditions revealed. In contrast, Cluster 3W presents lower persistence. This is due to the fact that the strong N-NE flow associated with this cluster has a short duration, as is usually the case for extreme events. By looking at the percentages of Clusters $2 \mathrm{~W}$ and 4 W for Days $D+1$ and $D+2$, we can infer that the synoptic conditions of Cluster $2 \mathrm{~W}$ seem to follow those of Cluster $4 \mathrm{~W}(20 \%)$ more frequently than do other synoptic conditions. This seems somewhat logical, as it can be derived from the common synoptic experience: when a deep depression lies over Ionian Sea, it usually moves eastwards and arrives in the Cyprus region after 1 or $2 \mathrm{~d}$, causing a strong N-NE flow over the Greek area. Cluster $5 \mathrm{~W}$ follows Cluster $4 \mathrm{~W}$ within a percentage of $15 \%$; the same happens with Cluster 3W, which follows Cluster 
a) CLUSTER IW

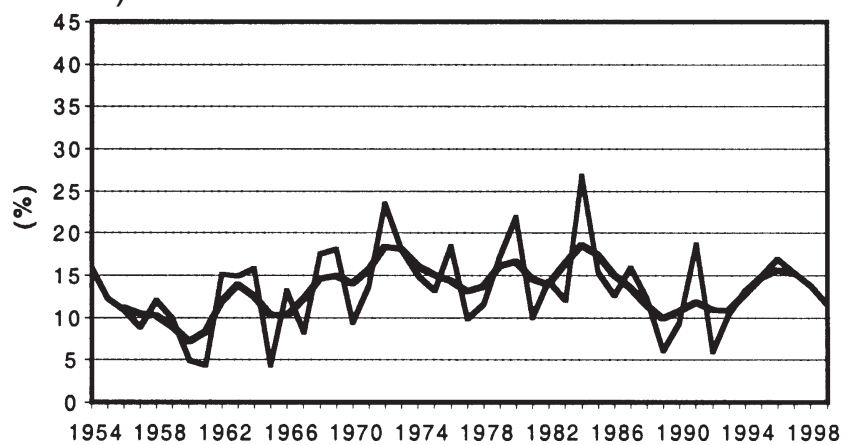

c)

CLUSTER 3W

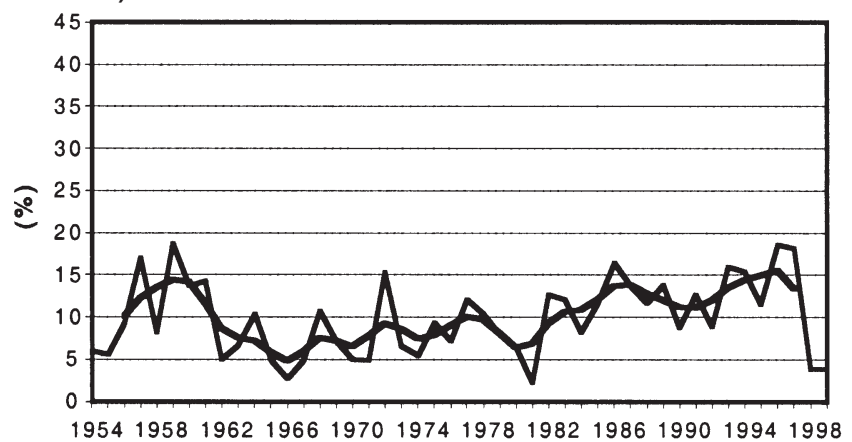

e)

CLUSTER 5W

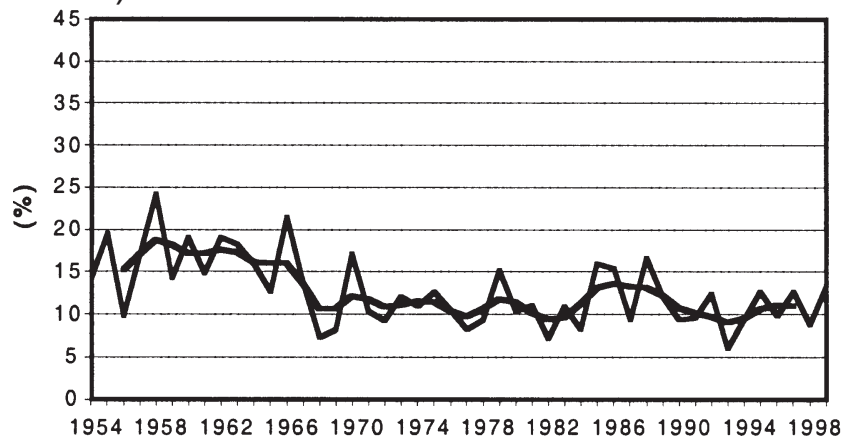

g)

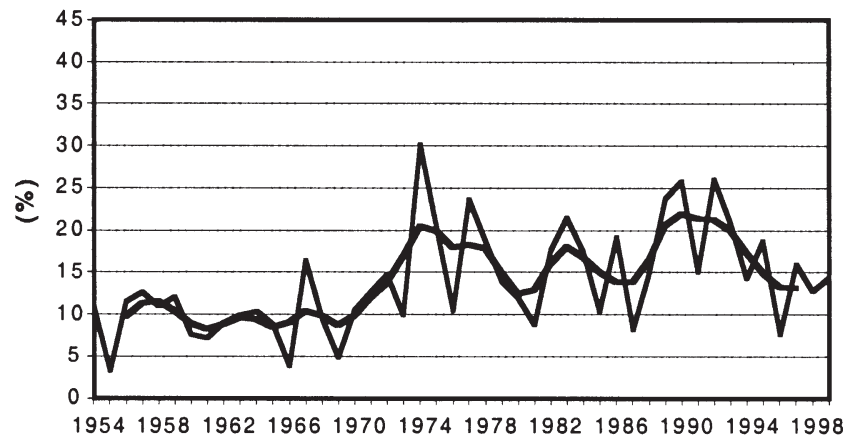

b)

CLUSTER 2W

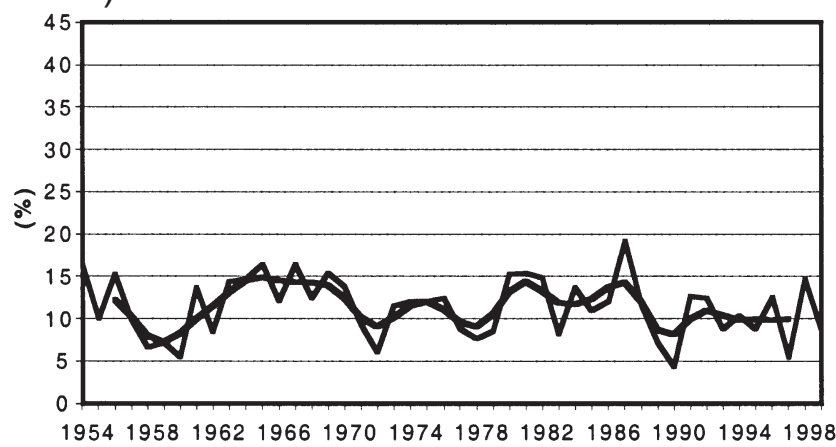

d) CLUSTER 4W

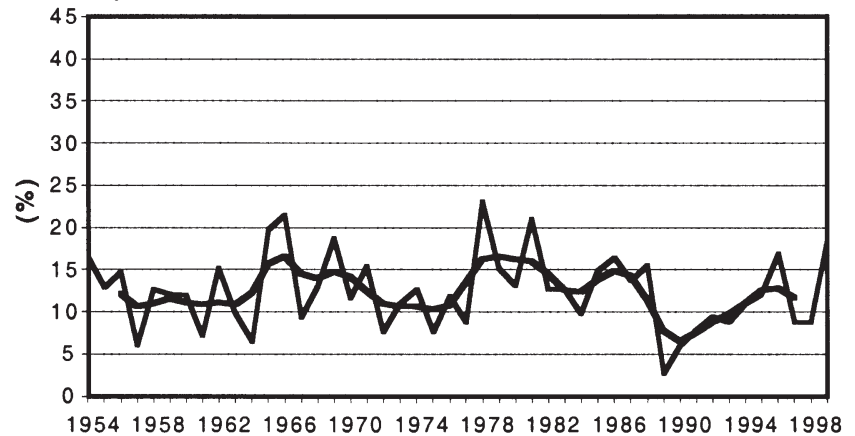

f)

CLUSTER 6W

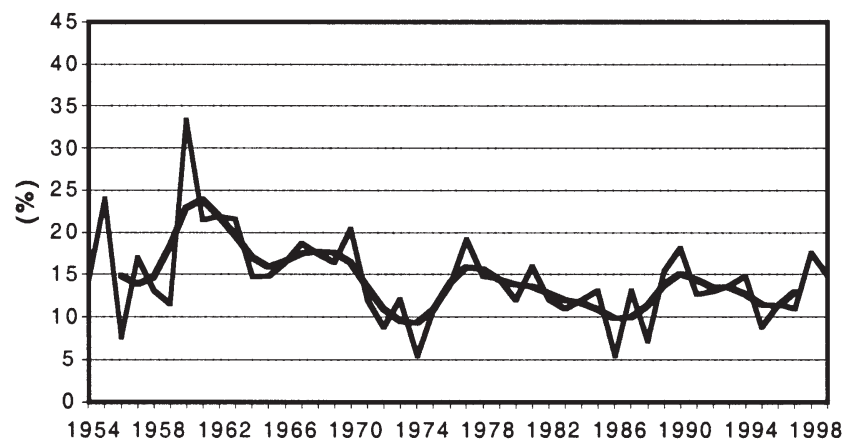

h) CLUSTER 8W

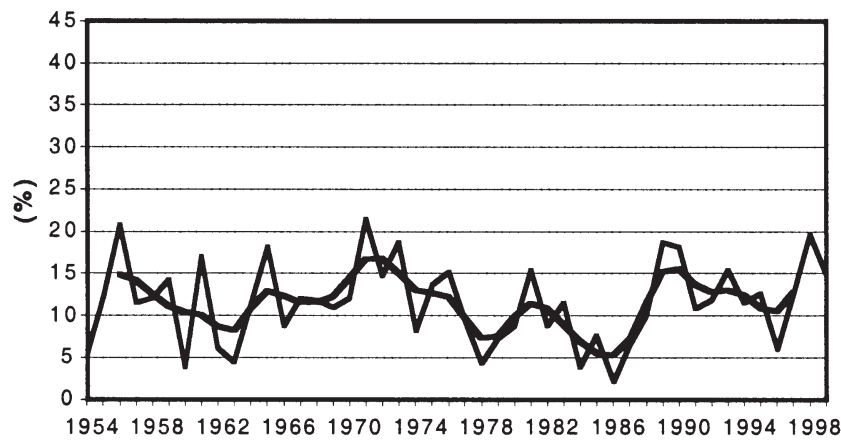

Fig. 6. Interannual variations of the frequency (\%) of the 8 cold-period clusters. Smoothed line represents moving average 
a)

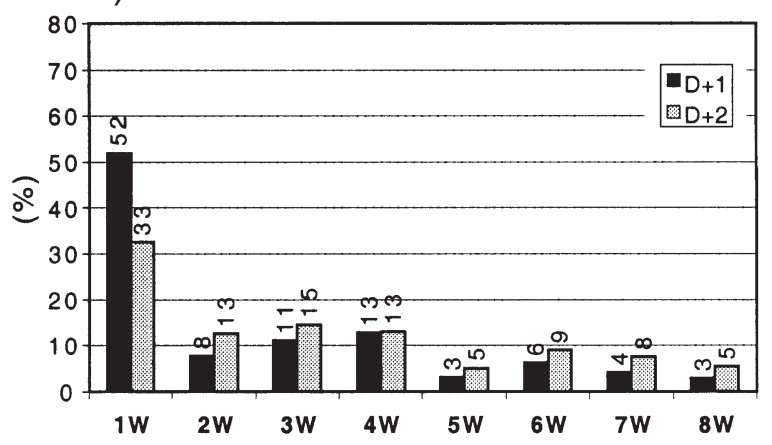

c)

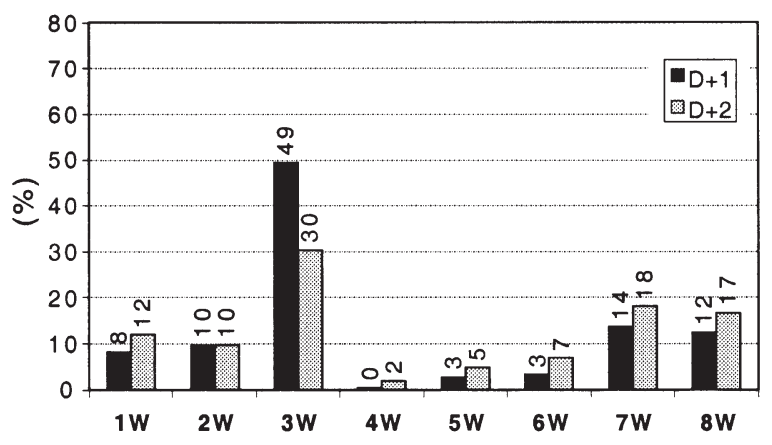

e)

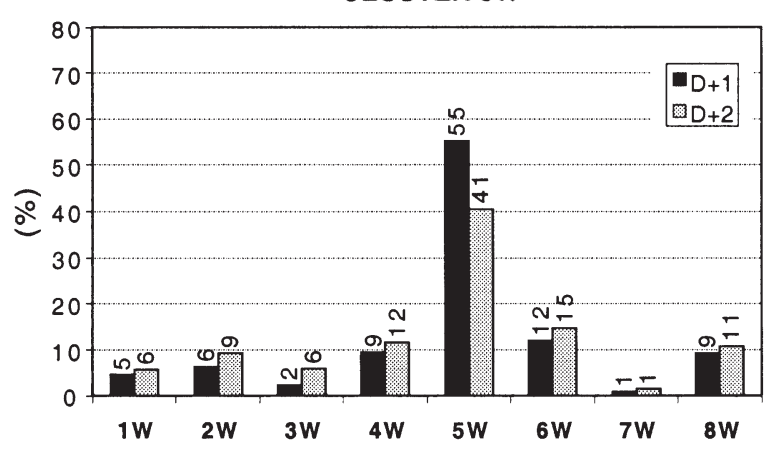

g)

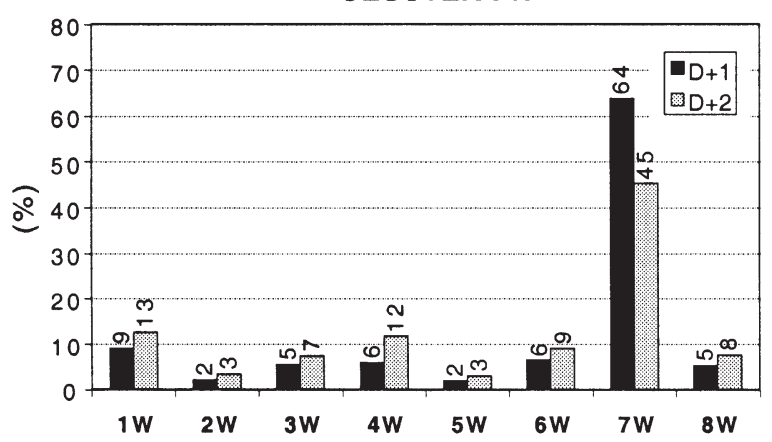

b)

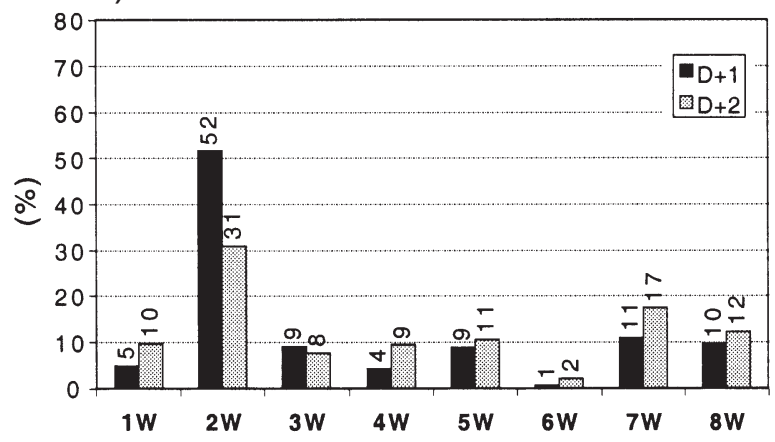

d)

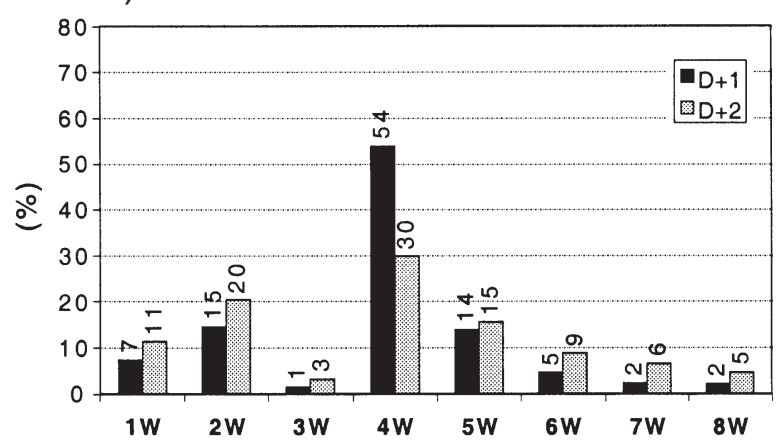

f)

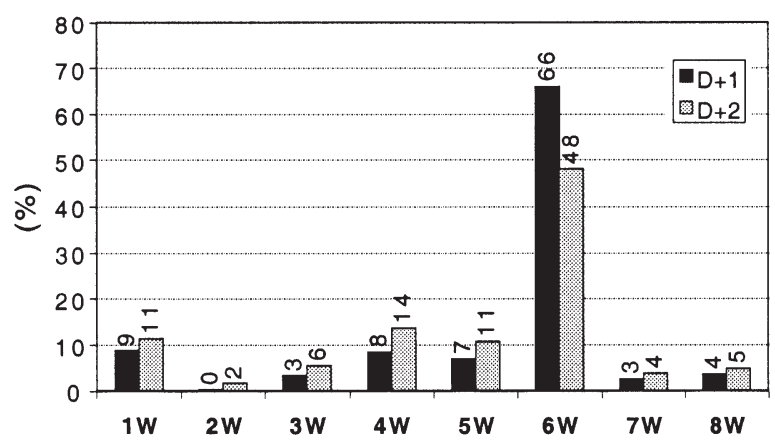

h)

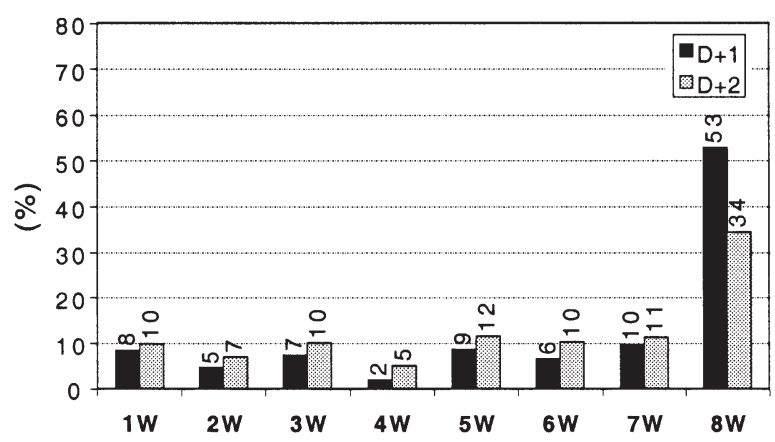

Fig. 7. Frequencies of cluster appearance for Days $D+1$ and $D+2$ for each of the 8 cold-period clusters 
a)

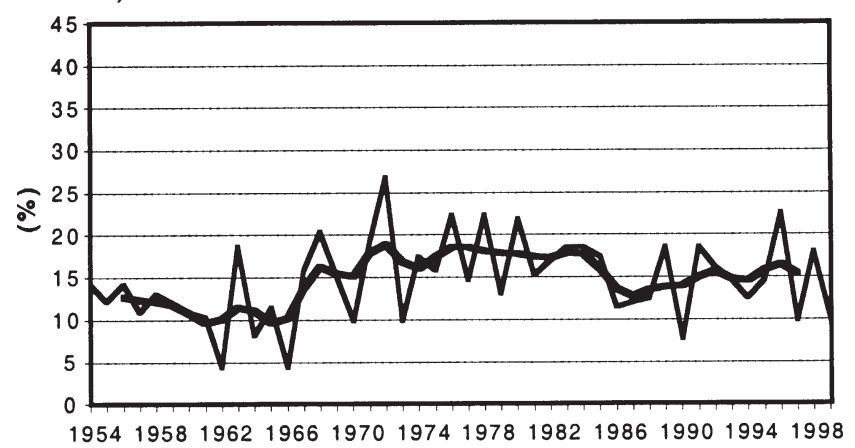

c)

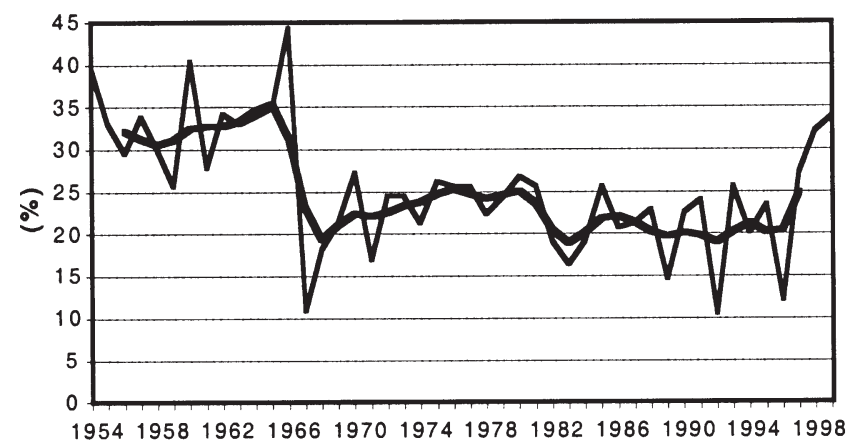

e)

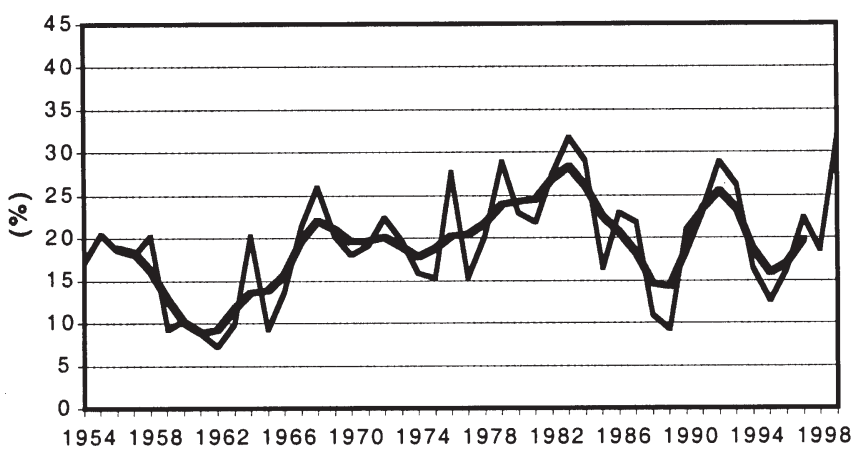

b)

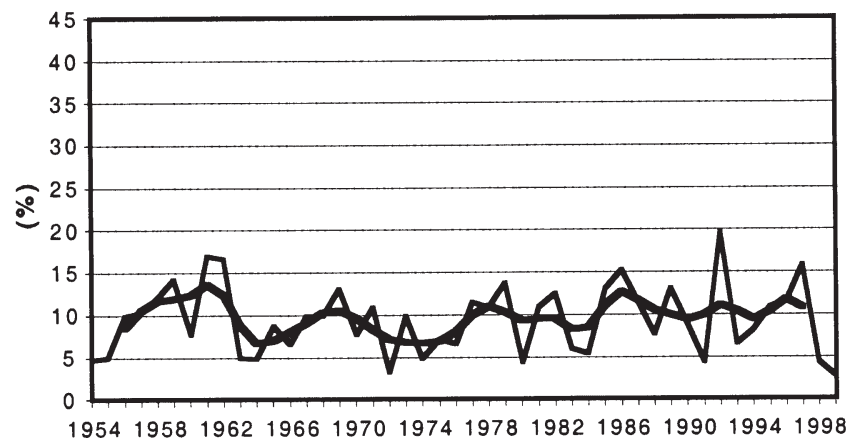

d)

CLUSTER 4S

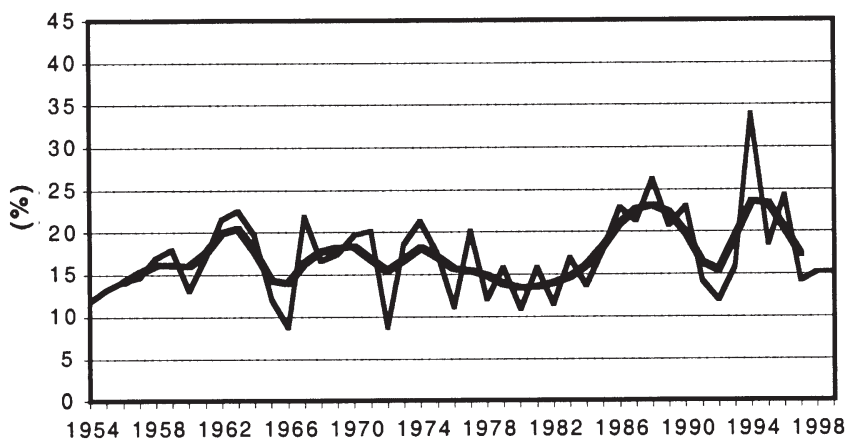

f)

\section{CLUSTER 6S}

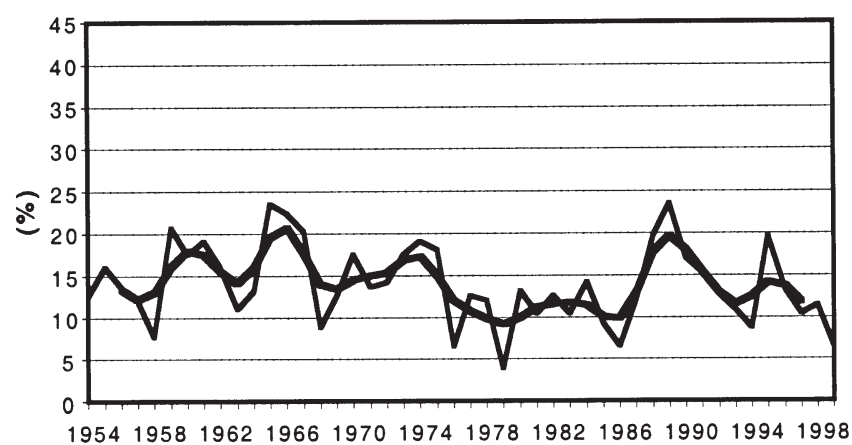

Fig. 8. Interannual variations of the frequency (\%) of the 6 warm-period clusters. Smoothed line represents moving average

1W within similar percentages. Cluster 7 follows Cluster 3 (percentage within $18 \%$ ) probably because in some cases the high-pressure system which lies over eastern Europe (Cluster 3) moves down to the south and stays over the Balkans during the days classified in Cluster 7.

\subsection{Warm period}

Among the time variations of the 6 clusters revealed (Fig. 8), the most interesting are those of Clusters 3S, 4S and 5S. More analytically, the frequency of Cluster 3S is about 50\% higher during 1954-1966 compared to that during 1967-1998. The frequency of Cluster 4S presented 2 main maxima during the later years: the first during the late 1980s and the second during the mid1990s. Thus, we can indirectly infer the high etesian wind frequency and/or intensity during these years. The frequency variation of Cluster $5 \mathrm{~S}$ is characterized by the minima of the early 1960s and the late 1980s and the maxima of the early 1980s and the early 1990s.

According to Fig. 9, Cluster 3S appears to be the most persistent $-70 \%$ for Day $D+1$ and $56 \%$ for Day $D+2$. This is due to the fact that the synoptic conditions corre- 
sponding to this cluster are the typical summer ones and thus are rarely interrupted by winter-like circulation disturbances and abrupt weather changes. Cluster 2S seems to be followed by Cluster 5 (32\%), as both synoptic conditions are anticyclonic and correspond to the same months. It is obvious that the anticyclone of Cluster $5 \mathrm{~S}$ derives from the attenuation of that of Cluster 2S. Clusters $3 \mathrm{~S}$ and $4 \mathrm{~S}$ follow each other with a remarkable level of agreement. Both clusters can be characterized as 'high summer' clusters, and their difference is related to the intensity of the etesian winds. When during the high summer months etesian intensity increases, we pass from Cluster 3S to Cluster 4S (24\%; Fig. 9c). The opposite is the case when the frequency of the etesians de- a)

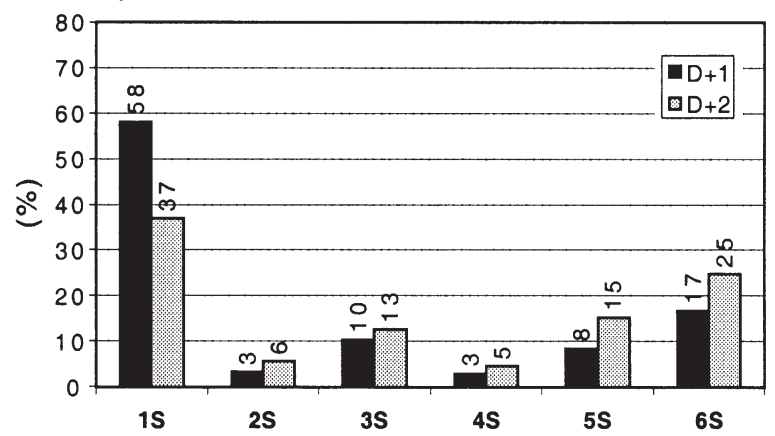

c)

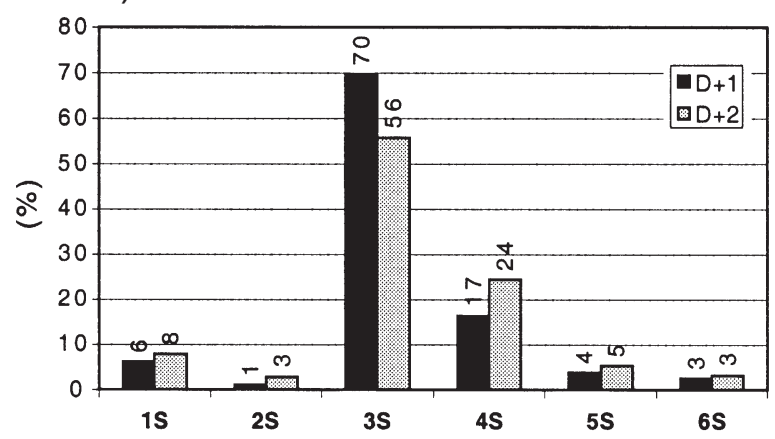

e)

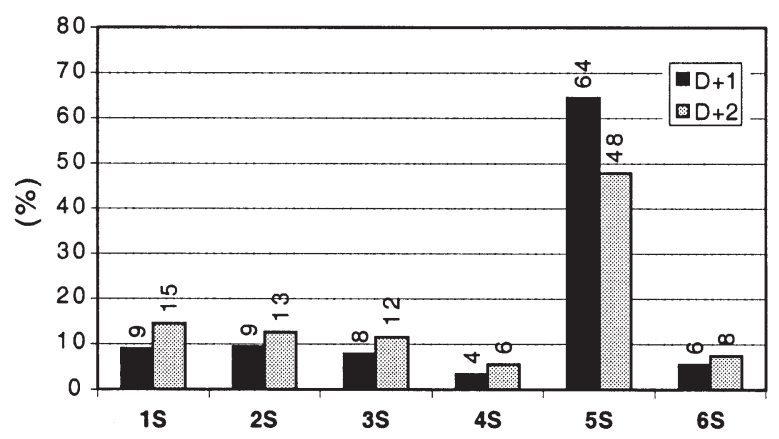

creases $(33 \%$; Fig. 9d). Finally, Clusters $1 \mathrm{~S}$ and $6 \mathrm{~S}$ prefer to follow each other, as they both correspond to the spring months (25 and $23 \%$; Fig. 9a,f). In one scenario, the pressure low that corresponds to Cluster $1 \mathrm{~S}$ moves eastward, giving up its position to a high-pressure pattern corresponding to Cluster 6S. In the other, Cluster 6S is replaced by Cluster $1 \mathrm{~S}$ as pressure lows pass across the area very often in this period of the year.

\section{CONCLUSIONS}

In this work, 2 synoptic classifications, 1 for the cold and 1 for the warm period of the year, were introduced

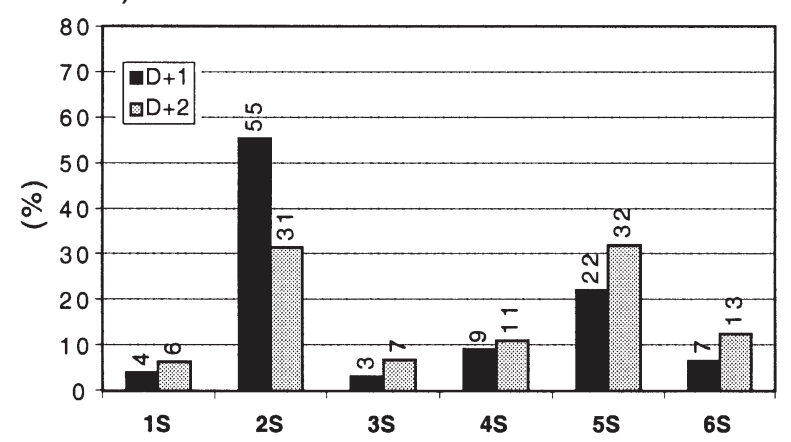

d)

CLUSTER 4S

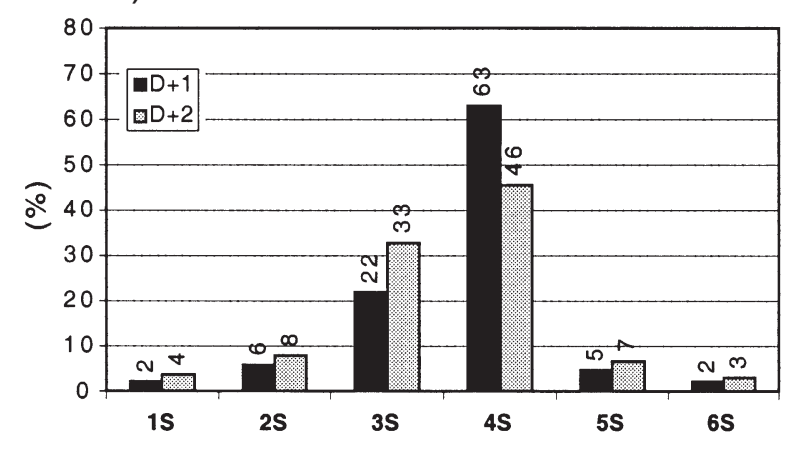

f)

CLUSTER 6S

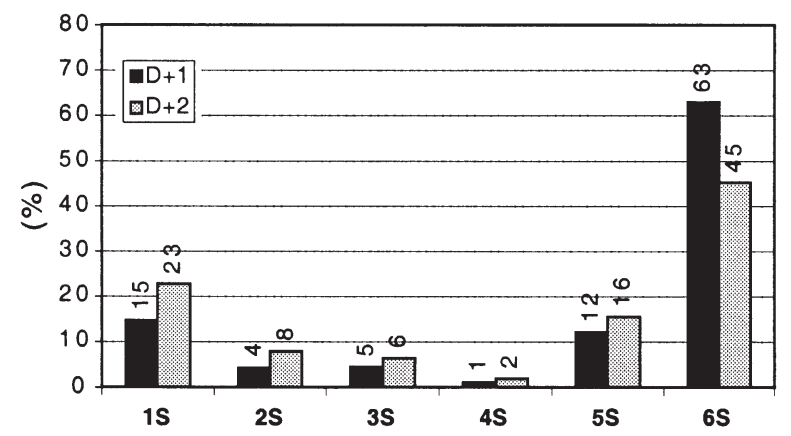

Fig. 9. Frequencies of cluster appearance for Days $D+1$ and $D+2$ for each of the 6 warm-period clusters 
for Athens, taking into account both the in situ meteorological conditions, and also the pressure distribution over Europe. Thus, the analysis differs from the past ones that were based either only on meteorological conditions or only on the synoptic patterns affecting an area. By using factor and cluster analyses, 8 clusters for the cold and 6 clusters for the warm period of the year were revealed. Each one of these clusters corresponds to a distinctive and well-defined synoptic condition. It was found that the resulting synoptic conditions present differences concerning the seasonal variation of their frequency, their interannual variability and their persistence, while some of the synoptic conditions were found to prefer a specific sequence. In addition, each cluster is different from the others not only in terms of pressure distribution but also with reference to meteorological conditions (temperature, humidity, radiation, etc.).

The innovative procedure introduced in this work seems very promising, and it could be followed by the climatologists and other scientists in the future in order to examine a variety of problems, such as morbidity, mortality and air quality, related to weather. For the cold period of the year, the interannual variations of the 8 synoptic patterns show a reduction of the cyclonic activity in the central Mediterranean during the late 1980s and early 1990s. For the summer months of July and August, the etesian winds were found to be dominant over the Aegean, while their impact on the weather conditions of Athens depends on their intensity; when the intensity is low, local circulation systems prevail instead of the synoptic flow.

Acknowledgements. The authors would like to thank the National Observatory of Athens and NCEP-NCAR, which kindly offered the data used in this study.

\section{LITERATURE CITED}

Bardossy A, Duckstein L, Bogardi I (1995) Fuzzy rule-based classification of circulation patterns. Int J Climatol 15: 1087-1097

Editorial responsibility: Andrew Comrie,

Tucson, Arisona, USA
Davis RE, Walker DR (1992) An upper air synoptic climatology of the western United States. J Clim 5:1449-1467

Hewitson BC, Crane RG (2002) Self organizing maps: applications to synoptic climatology. Clim Res 22:13-26

Jolliffe IT (1986) Principal component analysis. SpringerVerlag, New York

Kalkstein LS, Guanri T, Skindlov JA (1987) An evaluation of three clustering procedures for use in synoptic climatological classification. J Clim Appl Meteorol 26:717-730

Kalkstein LS, Nichols MC, Barthel CD, Greene JS (1996) A new spatial synoptic classification: application to air mass analysis. Int J Climatol 16:983-1004

Kalkstein LS, Sheridan SC, Graybeal DY (1998) A determination of character and frequency changes in air masses using a spatial synoptic classification. Int J Climatol 18: $1223-1236$

Kalnay E, Kanamitsu M, Kistler R, Collins W and 18 others (1996) The NCEP/NCAR 40-year reanalysis project. Bull Am Meteorol Soc 77:437-472

Kassomenos P, Flocas HA, Lykoudis S, Petrakis M (1998) Analysis of mesoscale patterns in relation to synoptic conditions over an urban Mediterranean basin. Theor Appl Climatol 59:215-229

Lamb HH (1972) British isles weather types and a register daily sequence of circulation patterns, 1861-1971. Geophysical Memoir 100. Meteorological Office, London

Maheras P (1980) Le problem des Etesiens. Mediterranee 4: 57-66

Maheras P (1988) The synoptic weather types and objective delimitation of the winter period in Greece. Weather 43: $40-45$

Matyasovszky I (1995) Impact of global climate change on temperature and precipitation in Greece. Appl Math Comput 70:1-31

McGregor RG, Bamzelis D (1995) Synoptic typing and its application to the investigation of weather air pollution relationships, Birmingham, United Kingdom. Theor Appl Climatol 51:223-236

Richman MB (1986) Rotation of principal components. Int J Climatol 6:293-335

Sharma S (1995) Applied multivariate techniques. John Wiley \& Sons, New York

Xoplaki E, Luterbacher J, Burkard R, Patrikas I, Maheras P (2000) Connection between the large-scale 500hPa geopotential height fields and precipitation over Greece during wintertime. Clim Res 14:129-146

Yao CS (1998) A loading correlation model for climatic classification in terms of synoptic climatology. Theor Appl Climatol 61:113-120

Yarnal B (1992) Synoptic climatology in environmental analysis. Studies in Climatology Series. Belhaven Press, London

Submitted: October 16, 2002; Accepted: February 5, 2003

Proofs received from author(s): May 13, 2003 